\title{
Models of Change in Organizations: The Case of XYZ Construction
}

\begin{abstract}
Submitted 30/04/20, $1^{\text {st }}$ revision $19 / 05 / 20,2^{\text {nd }}$ revision $29 / 06 / 20$, accepted $30 / 07 / 20$
\section{Lura Rexhepi Mahmutaj ${ }^{1}$, Arta Koka Grubi ${ }^{2}$}

Abstract:

Purpose: The objective of this paper is to present the understanding and application of models of change in organizations. It also highlights the importance of strategic change within firms and analyses planned and emergent models of strategic change management.

Design/Methodology/Approach: The paper is mainly focused on secondary data and analysed the XYZ construction, which is a multinational organization in UK that serves for major construction projects, and has implemented different models of change in an efficient manner.

Findings: In the paper, Force Field Analysis (FFA) and change kaleidoscope were discussed in relation to the case of XYZ construction. In the case of XYZ construction, management development and organization change were two activities linked together which brought success.

Practical Implications: Certainly, in order to have competitive advantage in today's dynamic marketplace, change models and tools must be implemented in organizations. The study offer new insights and transferability for practitioners involved in managing strategic change.

Originality/Value: This paper offers value for managers to analyse their strategic tools continuosly, and propose necessary changes to improve their performance.
\end{abstract}

Keywords: Emergent change, planned change, FFA and change kaleidoscope.

JEL Code: M14, O30.

Paper Type: Research study.

\footnotetext{
${ }^{1}$ University of Prishtina “Hasan Prishtina”, Kosovo, lura.rexhepi@uni-pr.edu

${ }^{2}$ Corresponding author, Dardania College, Kosovo, artakoka@gmail.com
} 


\section{Introduction}

Globalization results in many benefits toward productivity improvement, but it has affected also the economic crisis (The London Summit, 2009). Initially, the USA was affected by financial crisis, but it spread rapidly to other developed countries. This led to decrease on employment, production, and international trade all over the world. According to BBC News (2008), the economic crisis has increased the cost of living and unemployment in the UK. Also, prices of houses are decreasing in UK. Arnott (2009) points out that British Airways faced the biggest losses of $£ 292 \mathrm{~m}$, which means it had $13.7 \%$ decrease of revenues. Furthermore, 4500 UK people have lost their jobs in Royal Bank of Scotland (Treanor, 2009).

Balogun and Hailey (2004) point out that there is not one best model or tool for a change. Change depends on organization in specific situations or context. Change agents should have managerial and personal skills in order to adapt suitable changes. They should be focused on the needs of organizations, not on their own prejudices. The internal and external context of organization should be analyzed in order to gain an understanding of the need for change.

Today, understanding the practice of change management is not an option for organizations, but they are forced to implement changes in order to respond to these pressures and remain in the market. Organizations are trying to be more decentralized and change their traditional policies by implementing different strategic change models and tools for improvement. This paper will mainly focused on XYZ construction, which is a multinational organization in UK that serves for major construction projects, and has implemented different models of change in efficient manner (Burnes, 2004).

\section{Models of Change in Organizations}

This section provide brief introduction in strategic change context with the help of literature, followed by the models of change.

Table 1. Perspective from different authors on strategic change

\begin{tabular}{|l|l|}
\hline Citation & Definition \\
\hline (Muir, 1995) & $\begin{array}{l}\text { "Managing change is the essence of the manager's job and more } \\
\text { important in the long run than managing resources on a day-to-day } \\
\text { basis" (Muir, 1995:16). }\end{array}$ \\
\hline $\begin{array}{l}\text { (Balogun, } \\
\text { Strategic changes, }\end{array}$ & $\begin{array}{l}\text { "Change is about changing people, not organisations. Organisations } \\
\text { change when the managers and employees change their way of doing } \\
\text { business. It needs to be recognised that employees are an intrinsic } \\
\text { part of the change process" (Balogun, 2001:2) }\end{array}$ \\
\hline
\end{tabular}


Corporate strategy is heavily influence by increasing globalisation and dynamic business environment; every company is going through some changes and companies who struggle to sustain with incremental change may go through a transformational / radical change to avoid the worst situation (Wilkinson et al, 1995; Johnson et al., 2009). Any kind of change within an organization is through people. Thus, success and failures of change highly depend on employees from all levels and departments.

Some of the models of change which are useful to implement are planned, emergent, incremental, punctuated equilibrium, continuous, theory E, and theory O. Even though all these models can be used for different situations, this paper will be focused on most dominant models, such as planned and emergent change by critically evaluating their applicability with relevant examples in XYZ construction.

\subsection{Planned Change and Emergent Change}

Burnes (2004) points out that planned change was originated by Kurt Lewin in 1930 with the three-step model that includes unfreezing, moving, and refreezing. Unfreezing the existing attitudes happens when a person is ready to change. This may be done through team building, or any other management development to show that there is a problem which should be resolved and make people aware of the need for change. Moving means that the person should be motivated to learn and be comfortable with new ways. This can be done by analyzing the current situation, identify options, and come up with a solution which will include changes in behaviors and values. Lastly, refreezing new values happens when new ways of thinking become stable within a group. This may include new recruitment and reward systems.

Emergent change is a processual approach to change, that involves deeper analysis to understand the complexity of problems, strategy, structure, culture, and people in organizations (Burnes, 2004; Dawson, 1994). This is because there are unexpected events during the changing process. Organizations should create continuous learning environment in order to implement changes in accordance to market development and their strategy (Burnes, 2004; Pettigrew and Whipp, 1993). According to Burnes (2004), it was claimed by Stickland (1998) that bottom up approach is used in organizations because of the rapid environmental changes where senior managers are not capable to respond effectively to all problems, which leads to unintended outcomes from different actions. So, organizational structure is being more flexible and it is giving authority to employees to influence decisions. They are trying to be focused more in customers' value by developing cooperation between departments and exchanging knowledge between each other (Burnes, 2004). Also, changing roles and attitudes for employees take place. Employees should understand the complexity of the current situation and get better understanding of the market, customers, and competitors (Burnes, 2004; Beer et al., 1993). Hence, it is crucial for managers to increase commitment of all employees in the organization (Burnes 2004; Buchanan 
and Boddy, 1992). Also, change agents play important role because they have the necessary skills, knowledge, and experience to achieve successful emergent change (Burnes, 2004; French and Bell, 1995).

\subsection{XYZ Construction Using Planned Change and Emergent Change}

There is a case of $\mathrm{XYZ}$ construction that within four years changed its culture and structure by using emergent and planned approaches. According to Burnes (2004), Allaire and Firsirotu (1984) there is strong relationship between culture and structure, and when one is changed, there is probably a need to change the other. $\mathrm{XYZ}$ construction has done that.

XYZ construction is a highly competitive organization in UK. There was poor relationship between contractors and sub-contractors, and they had authoritarian director who was not liked by others. However, when he retired, there was low performance management of organization, and a new director was appointed who has done transformation of culture of organization by using emergent change. The strategy of managing director was to improve customer service by introducing new practices and change of attitudes of individuals in organization. The director knew that there is a need for cooperation and that is why team meetings between managers and staff were organized. He introduced Kaizen approach to perform improvements at low cost, develop team, empower employees, and acquire new skills for employees. The managing director knew how to communicate this initiative and made them believe that it will work. Then customer care programme was developed to understand better customers' needs and values. This company invested on employees to make sure that they have the necessary skills and attitudes toward their change roles to deal with customers efficiently. All his process was done within four years, and XYZ transformed its culture with sufficient changes that lead to high performance. Indeed, the culture change was experimental change that decentralized the organization by changing behaviors and attitudes of individuals (Burnes, 2004).

Additionally, the managing director used planned change to restructure the organization because of the poor relationship between departments and functions in head office. They had lack of communication and team working and they considered each other rivals. He hired a change consultant, who helped to develop change process with different activities. The first activity was to understand change readiness and it involved different interviews to discuss and analyze the problem of reducing the number of departments. Some of employees did not like this change, because they considered that opportunities for career developments will diminish. However, most of the employees were open to change because of the trust they created to the director who brought positive changes before. In the second activity, workshops were organized for senior management team in order to propose a new structure. Based on evaluation criteria, they selected the preferred structure. The new structure was process-oriented flat, which involved team development and new roles. There was resistance of managers to change because their power and 
responsibility was reduced, and employees had to work as a team even with people they did not like. Then team members communicated the new structure to lower level of organization and explained its impact on them. Employees had to change the office and training took place to develop new skills. Lastly, managers evaluated the new structure by presenting steps to increase effectiveness and develop team. This was planned change, directed by top management with clear objectives in place (Burnes, 2004).

\subsection{Criticisms of Planned Change and Emergent Change}

Even though planned change has shown success in 1960s and 1970s and many organizations have used it, there are many criticisms toward its validity and efficiency. According to Burnes (2004), Wooten and White (1999) this approach is top-down, where direction and control are involved. Also, Cummings and Worley (2008) argue that planned change is not efficient to implement in organizations because unexpected events can happen by having demand variation, different expectations of stakeholders, and technological changes. Therefore, it is impossible for organizations to intervene with step by step approach, which takes long time to be implemented, and requires high commitment. Moreover, planned change brings incremental changes, and it is not capable to bring transformational changes, as in this turbulent environment, organizations should act rapidly (Burnes, 2004; Dunphy and Stace, 1993; Harris, 1985; Miller and Friesen, 1984; Schein, 1985). This approach cannot be used for all kind of situations in organisations (Burnes, 2004; Dunphy and Stace, 1994).

Indeed, the criticism against planned approach has started in 1980s because change should be continuous, and it cannot be planned as there are unpredictable circumstances in modern organizations. This shows that organizations should use bottom-up approach in order to empower employees and ensure that they possess the skills and motivation to remove the barriers of environment and implement emergent change (Burnes, 2004).

Even though emergent change has become a very popular approach in organizations, it has some criticisms which question its applicability. Emergent change assumes that all organizations operate in complex environment. As this is not the case, this approach ignores the organizations that need incremental or punctuated equilibrium changes (Burnes, 2004). Also, proponents of emergent change are against the planned change that uses Lewin's three-step model, but they also suggest that the emergent change has a beginning, middle, and an end (Burnes, 2004; Dawson, 1994; Kotter, 1996; Pettigrew et al., 1992). Furthermore, emergent change emphasizes the organizational learning, but there is a question whether managers are willing to learn, and share knowledge because of limitation of their power (Burnes, 2004; Whittington, 1993).

\section{Tools of Change in Organizations}


There are different tools of change that organizations are using in order to improve their performance, such as force field analysis (FFA), change kaleidoscope, total quality management, PESTEL, SWOT analysis, cultural web, McKenzie 7S, organizational development, growth share matrix, and benchmarking. In this paper, FFA and change kaleidoscope will be discussed in relation to the case of XYZ construction.

\subsection{Force Field Analysis (FFA)}

FFA is a tool developed by Kurt Lewin, which is about identifying driving forces and restraining forces toward a new situation with an arrow in a diagram (Burnes, 2004). Forces are identified based on internal or external environment, such as stakeholders' influence, reward and punishment systems, resources and PEST factors. This helps an organization to analyze the problem and decide whether the change should be implemented or not (Schwering, 2003). Also, with the help of FFA, organizations can strengthen the factors that push the change and reduce the impact of factors that prevent it. Based on planned change that XYZ construction has used to restructure its organization by reducing the number of departments. Figure 1 shows FFA by identifying its driving and restraining forces toward this change.

Figure 1. FFA in XYZ Construction Company

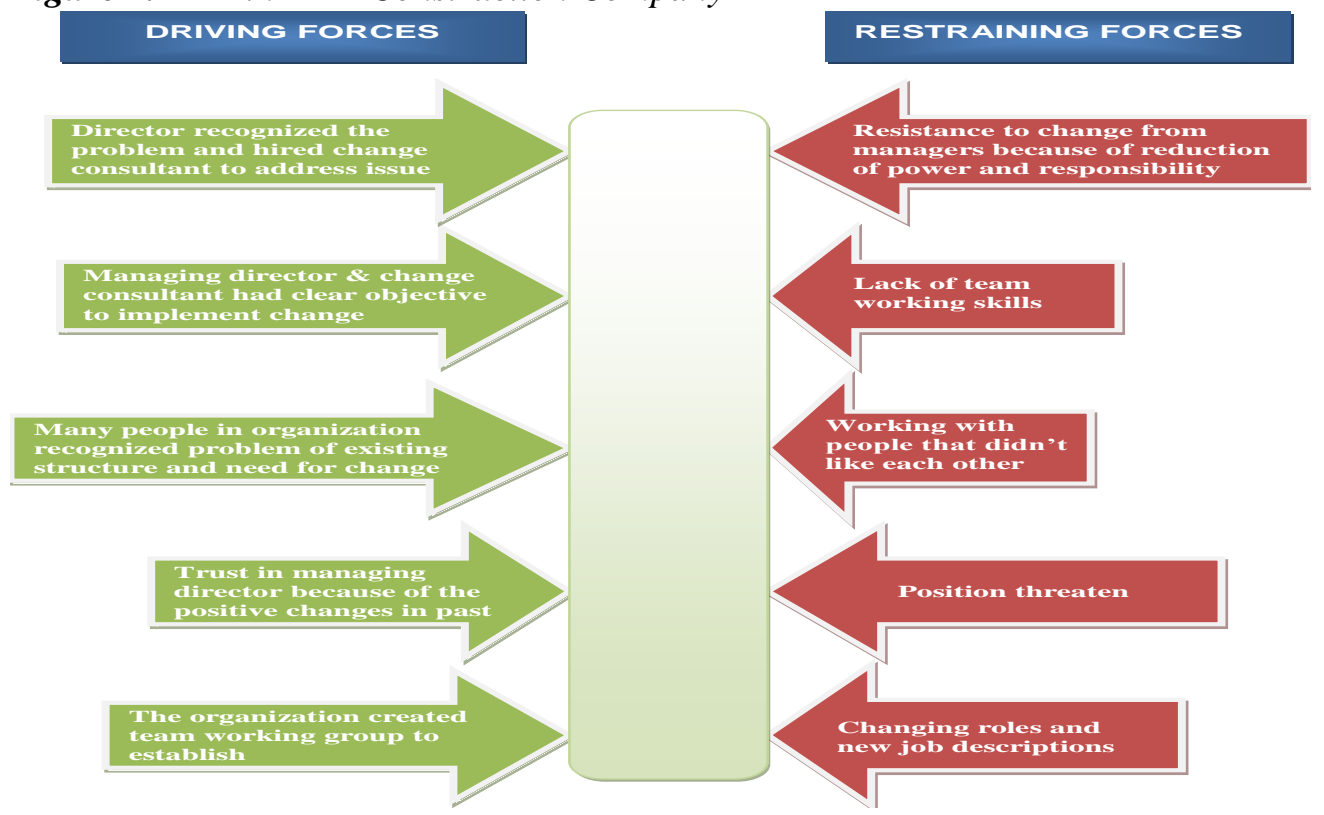

Besides the successful usage of FFA in XYZ construction, there are many other organizations that benefited from this tool. Schwering (2003) explains the case of a US civil engineering firm which had a problem with stakeholders, and with excellent planning team, it has identified and resolved the problem by having collective 
understanding of the system. Also, Lan and Lee (1997) discuss about policies that affected women in workforce in Singapore by using FFA. Because women had to take care of children and the cost of hiring a maid was high, the government started to provide part-time job for women, so they can work and take responsibility at home.

Decision makers who are involved in planning change should have the right skills and experience in order to implement it successfully. Schwering (2003) criticizes FFA for being dependent in planning groups who might mention only the factors that they are aware of. Also, it includes bias decision making based on mental shortcuts, which might lead to poor results in implementing change due to the uncertainty.

\subsection{Change Kaleidoscope}

Another tool which is discussed in this paper is change kaleidoscope, which is used to assess the change process in organization by mapping the change context (Balogun and Hailey, 2004). This is diagnostic framework that contains outer, middle, and inner rings to identify organizational strategic context, specific features of change, and design choices. It enables organization to identify the type of change needed for specific situations through eight contextual features, such as time, scope, preservation, diversity, capability, capacity, readiness, and power (Balogun and Hailey, 2004). Based on emergent model, XYZ construction changed organizational culture in order to change employees' behaviors and attitudes as well as to improve management performance. Figure 2 shows change kaleidoscope tool that analyzes this case.

Figure 2. Change Kaleidoscope in XYZ Construction Company

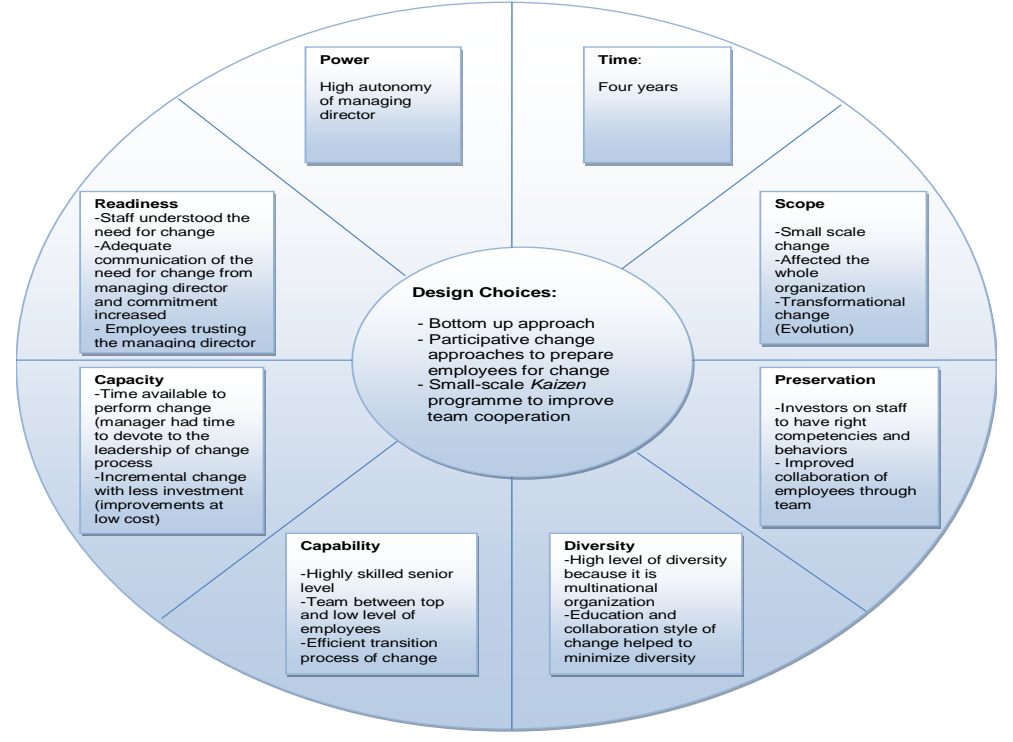




\section{Conclusion}

In this modern world, there is a rapid change which is affecting all organizations and managers. In order to remain in the market, organizations are enforced to implement the right change models and tools to resolve their problems. Even though planned and emergent change models have some criticisms toward their validity, they have been effective in organizations for different situations. Planned approach is effective when there are needed small-scale changes in a stable environment with the aim to improve performance by collaboration and changing behaviors of people (Burnes, 2004). On the other hand, emergent approach is effective when there is turbulent environment and there are needed large-scale changes in order to change the culture by collaboration and political dimensions (Burnes, 2004). In the case of XYZ construction, management development and organization change were two activities linked together which brought success (Burnes, 2003). There are proponents and critics toward both approaches, but Burnes (2004) suggest that it is the ability of managers to know which approach is suitable for a certain situation within organization.

Furthermore, there are many tools of change that have brought success to organizations, and this paper was focused on analyzing XYZ construction based on FFA and change kaleidoscope. Even though FFA has helped many organizations to identify driving and restraining forces to implement change, there are some criticisms regarding its effectiveness. Indeed, individuals in organizations should be prepared mentally for change and have positive attitude for it. It is the challenge of managers to find the best way to explain the current situation and convince individuals throughout organizations for the need for change (Knippen and Green, 1997). One of the reasons why change management fails is that managers do not possess the right skills to develop change models and tools in organizations. Certainly, in order to have competitive advantage in today's dynamic marketplace, change models and tools must be implemented in organizations.

\section{References:}

Arnott, S. 2009. British Airways nosedives to unprecedented $£ 292 \mathrm{~m}$ loss. Retrieved from: http://www.independent.co.uk/news/business/news/british-airways-nosedives-tounprecedented-163292m-loss-1816691.html

Balogun, J. 2001. Strategic changes. Mangement Quaterly, Part 10, 2-11.

Balogun, J., Hailey, H.V. 2004. Exploring Strategic Change $2^{\text {nd }}$ ed. Edinburgh Gate, Harlow, Essex, Pearson Education Limited.

BBC News. 2008 Darling warns economic crisis. Retrieved from: http://news.bbc.co.uk/1/hi/7589291.stm

Burnes, B. 2004. Managing Change: A strategic Approach to Organisational Dynamics. London, Financial Times.

Burnes, B. 2004. Emergent change and planned change - competitors or allies? The case of XYZ construction. International Journal of Operations \& Production Management, 24(9), 886-902. 
Burnes, B. 2003. Managing change and changing managers from ABC to XYZ. International Journal of Management Development, 22(7), 627-642.

Cummings, T.G., Worley, C.G. 2008. Organization Development \& Change. Cengage Learning, Nelson Education Ltd., 41-44.

Johnson, G., Scholes, K., Whittington, R. 2009. Fundamentals of strategy. Pearson Educational Limited.

Knippen, T.J., Green, B.T. 1997. How to respond to Change. Journal of Workplace Learning, 9(1), 17-19.

Lan, L.L., Lee, J. 1997. Force-field analysis on policies affecting working women in Singapore. Journal of Management Development, 16(1), 43-52.

Muir, J. 1995. Managing Change. Work Study, 44(2), 16-18.

Schwering, E.R. 2003. Focusing leadership through force field analysis: new variations on a venerable planning tool. Leadership \& Organization Development Journal 24(7), 361370 .

The London Summit. 2009. Context of the global financial crisis. Retrieved from: http://www.londonsummit.gov.uk/en/summit-aims/economic-crisis/context-of-financialcrisis/

Treanor, J. 2009. RBS axes 3,700 jobs as taxpayer stake hits $84 \%$. Retrieved from: http://www.guardian.co.uk/business/2009/nov/02/rbs-slash-costs-cuts-jobs

Wilkinson, A., McCabe, D., Knights, D. 1995. What is happening in "quality" in the financial services? The TQM Magazine, 7(4), 9-12. 